\title{
Article
}

\section{Pulping and pretreatment affect the characteristics of bagasse inks for 3D printing}

Gary Chinga-Carrasco, Nanci V. Ehman, Jennifer Pettersson, Maria Vallejos, Malin Brodin, Fernando E. Felissia, Joakim Hakansson, and María Cristina Area

ACS Sustainable Chem. Eng., Just Accepted Manuscript • DOI: 10.1021/

acssuschemeng.7b04440 • Publication Date (Web): 12 Feb 2018

Downloaded from http://pubs.acs.org on February 15, 2018

\section{Just Accepted}

"Just Accepted" manuscripts have been peer-reviewed and accepted for publication. They are posted online prior to technical editing, formatting for publication and author proofing. The American Chemical Society provides "Just Accepted" as a service to the research community to expedite the dissemination of scientific material as soon as possible after acceptance. "Just Accepted" manuscripts appear in full in PDF format accompanied by an HTML abstract. "Just Accepted" manuscripts have been fully peer reviewed, but should not be considered the official version of record. They are citable by the Digital Object Identifier (DOI®). "Just Accepted" is an optional service offered to authors. Therefore, the "Just Accepted" Web site may not include all articles that will be published in the journal. After a manuscript is technically edited and formatted, it will be removed from the "Just Accepted" Web site and published as an ASAP article. Note that technical editing may introduce minor changes to the manuscript text and/or graphics which could affect content, and all legal disclaimers and ethical guidelines that apply to the journal pertain. ACS cannot be held responsible for errors or consequences arising from the use of information contained in these "Just Accepted" manuscripts. 
ACS Sustainable Chemistry \& Engineering. Last update: 09.02.2018.

\title{
Pulping and pretreatment affect the characteristics of bagasse inks for 3D printing
}

Gary Chinga-Carrasco ${ }^{a}$, Nanci V. Ehman ${ }^{b}$, Jennifer Pettersson ${ }^{c}$, María E. Vallejos $^{b}$, Malin W. Brodin $^{a}$, Fernando E. Felissia ${ }^{b}$, Joakim Håkansson ${ }^{c}$, María C. Area $^{b}$

*Corresponding author: gary.chinga.carrasco@rise-pfi.no

${ }^{a}$ RISE PFI, Høgskoleringen 6b, 7491 Trondheim, Norway

${ }^{\mathrm{b}}$ Instituto de Materiales de Misiones (IMAM), Félix de Azara 1552, (3300) Posadas, Misiones, Argentina

${ }^{c}$ RISE Bioscience and Materials, Brinellgatan 4, 50462 Borås, Sweden

\begin{abstract}
Bagasse is an underutilized agro-industrial residue with great potential as raw material for the production of cellulose nanofibrils (CNF) for a range of applications. In this study, we have assessed the suitability of bagasse for production of CNF for three-dimensional (3D) printing. Firstly, pulp fibers were obtained from the bagasse raw material using two fractionation methods, i.e. soda, and hydrothermal treatment combined with soda. Secondly, the pulp fibers were pre-treated by TEMPO-mediated oxidation using two levels of oxidation for comparison purposes. Finally, the CNFs were characterized in detail and assessed as inks for 3D printing. The results show that CNF produced from fibers obtained by hydrothermal and soda pulping were less nanofibrillated than the corresponding material
\end{abstract}


ACS Sustainable Chemistry \& Engineering. Last update: 09.02.2018.

produced by soda pulping. However, the CNF sample obtained from soda pulp was cytotoxic, apparently due to a larger content of silica particles. All the CNF materials were 3D printable. We conclude that the non-cytotoxic CNF produced from hydrothermally and soda treated pulp, can potentially be used as inks for 3D printing of biomedical devices.

Keywords: nanocellulose, chemical modification, 3D printing, characterization, biomedical devices.

\section{Introduction}

Sugarcane bagasse is one of the most important agro-industrial residues in sugarcaneproducing regions. Only the Brazilian sugarcane industry was estimated to generate more than 160 million tons of bagasse in $2015-2016 .{ }^{1}$ Diversification of the sugarcane industry by producing byproducts from the renewable bagasse residue, offers important advantages by reducing the dependence on the marketing of the single main product (i.e. sugar). Sugarcane bagasse has a typical composition of $43-45 \%$ cellulose, $21-23 \%$ lignin, $25-32 \%$ hemicelluloses (mainly xylan) and minor amounts of extractives and ash. In a sugarcane biorefinery, refined components could be obtained from bagasse by application of appropriate fractionation and pulping methods.

Hydrothermal (HT) treatment is used in the fractionation of hardwoods, canes, and grasses to extract hemicelluloses. ${ }^{2}$ Extraction of hemicelluloses as oligosaccharides and monosaccharides is achieved, and these can be used for different applications. ${ }^{2}$ By sodaanthraquinone pulping a sulfur-free lignin can be separated from the bagasse pulp. ${ }^{3}$ Compared to other non-wood fibers, bagasse pulp has been considered advantageous for 
ACS Sustainable Chemistry \& Engineering. Last update: 09.02.2018.

the manufacture of paper, when considering for collection, manipulation, and storage. ${ }^{4}$

Furthermore, bagasse pulp can be used for the production of cellulose nanofibrils (CNF). ${ }^{5}$

CNF have been obtained from several feedstocks including forest and agricultural biomass, e.g. from wood industrial waste, ${ }^{6-8}$ agricultural waste ${ }^{9-11}$ and bagasse ${ }^{5}$. CNF typically have lengths in the micrometer scale ${ }^{12}$ and widths in the nanometer scale $(<100 \mathrm{~nm})^{13}$. In addition to different chemical and enzymatic pretreatments, processing variables can also be applied to tailor the morphology and surface chemistry of the CNF. ${ }^{13-16}$ Bagasse pulp has proven to be a suitable raw material for CNF production, ${ }^{5,17-19}$ and the properties of the CNFs are analogous to those of CNF produced from wood pulps. ${ }^{16,20,21}$ However, the effect of a given pulping method and the chemical composition of the produced pulp fibers on the corresponding CNF characteristics, has not been assessed.

Among the various technologies that exist for 3D printing of hydrogels, extrusion systems have been some of the preferred methods, as recently described by Rod et al. ${ }^{22}$ 3D printing of hydrogels has gained considerable interest, mainly due to the prospect of engineering functional tissue for replacing or repairing human tissue and organs ${ }^{23}$. Other biomedical applications that have been proposed for 3D printing techniques include the in-situ production of advanced wound dressings, ${ }^{24}$ cell patterning for cell-based sensors, ${ }^{25}$ development of drug delivery systems ${ }^{26}$ and for in vitro drug and toxicity testing. ${ }^{22}$

Inks for 3D printing need to be fluid enough to be pressed through the nozzle during printing, yet they need to be viscous during printing to be deposited in 3D patterns and to retain the 3D structure after printing. CNF hydrogels based on TEMPO-mediated oxidation 
ACS Sustainable Chemistry \& Engineering. Last update: 09.02.2018.

are interesting candidates for inks due to their shear thinning properties ${ }^{27}$, which enables them to flow easily when shear is applied (i.e. when pressed through the nozzle) and to consolidate after the shear is released.

The fractionation and pulping process, as well as the chemical pretreatment (TEMPOmediated oxidation) of the bagasse pulp, is expected to influence the chemical composition and characteristics of the CNF. According to the best of our knowledge, the influence of the hydrothermal treatment (prior to the alkaline pulping) on the production of CNF and its suitability as 3D printing ink has not been addressed. In this work, we studied the suitability of bagasse for the production of CNF inks for 3D printing, and how some properties of the inks differed when using bagasse pulps with different characteristics. Bagasse was processed by alkaline cooking and by a combination of hydrothermal treatment and alkaline cooking. The resulting pulps were treated by two levels of TEMPO-mediated oxidation before CNF production by homogenization. Important characteristics such as morphology, surface chemistry and potential cytotoxicity of the CNF inks were assessed.

\section{Materials and methods}

\section{$\underline{\text { Materials }}$}

Sugarcane bagasse was supplied by a local mill (San Javier Sugar Mill, Misiones, Argentina). Bagasse pith was wet-depithed to break its structure by a Bauer disc refiner (plate gap of $0.01 \mathrm{in}$ ) and the pith was then removed by screening, using a plate with $2 \mathrm{~mm}$ wide slits (Wenmber).

Pulping 
ACS Sustainable Chemistry \& Engineering. Last update: 09.02.2018.

Hydrothermal treatment was accomplished in a $4 \mathrm{~L}$ pressurized reactor heated with direct vapor. Treatment conditions were: initial and final liquid/bagasse ratio of $2 / 1$ and 5/1 respectively, temperature $180^{\circ} \mathrm{C}$, time of heating $9 \mathrm{~min}$, and time at maximum temperature $20 \mathrm{~min}$.

The alkaline cooking was performed in an MK digester of 7 liters capacity with liquor recirculation. The conditions of this treatment were: liquid/bagasse ratio of 10/1; temperature $170^{\circ} \mathrm{C}$, time of heating $80 \mathrm{~min}$; time at maximum temperature $60 \mathrm{~min}$, alkaline charge $16 \%$ and $18 \% \mathrm{NaOH}$ on oven dry (od) bagasse applied on material hydrothermally treated and untreated, respectively. For the charge of $\mathrm{NaOH}$ to be equivalent in both cases, in the BHS pulp, the alkali, which is neutralized by the formation of acetic acid coming from the reaction of the acetyl groups, was discounted. It is important to mention that the hydrothermal treatment and the soda pulping conditions applied In this study were selected on the base of previous works. ${ }^{28,29}$

\section{Chemical composition}

Raw material and pulps were characterized according to NREL-LAP standards, including total solids and moisture (NREL/TP-510-42621), extractives (NREL/TP-510-42619), glucans, xylans and arabinans, acetyl groups, and lignin soluble and insoluble in acid (NREL/TP-510-42618). The quantification of sugars, organic acids, and degradation products was carried out by liquid chromatography HPLC (Waters Corp. Massachusetts, USA), using a column AMINEXHPX97H (BIO-RAD) with the following chromatographic conditions: eluent: $\mathrm{H}_{2} \mathrm{SO}_{4} 4 \mathrm{mM}$, flow: $0.6 \mathrm{~mL} / \mathrm{min}$, temperature: $35^{\circ} \mathrm{C}$, detector: refraction index and diode array. 
ACS Sustainable Chemistry \& Engineering. Last update: 09.02.2018.

The quantification of homopolymers (glucans, xylans, and arabinans) in the solid was carried out multiplying sugars by the hydrolysis stoichiometric factors: 0.88 (or 132/150) for sugars with five carbons (xylose and arabinose) and 0.90 (162/180) for sugars with six carbons (glucose). Kappa number was determined according to ISO 302.

\section{CNF production}

The CNFs were produced according to Nordli et al. $(2016)^{30}$ and based on 2,2,6,6tetramethylpiperidinyl-1-oxyl (TEMPO)-mediated oxidation, to obtain CNF with appropriate characteristics for biomedical use. After washing the fibers with MQ water, the pulp fibers were autoclaved in $0.1 \mathrm{M} \mathrm{NaOH}$ for two hours and then washed with $\mathrm{MQ}$ water. This procedure was performed three times.

For each series, TEMPO-mediated oxidation was applied, ${ }^{13}$ using $3.8 \mathrm{mmol}$ and $6.0 \mathrm{mmol}$ hypochlorite ( $9 \% \mathrm{NaClO}$ ) per gram of pulp fibers (Table 1). The amount of TEMPO and $\mathrm{NaBr}$ used in the reactions were $0.0125 \mathrm{~g} / \mathrm{g}$ of fibers and $0.125 \mathrm{~g} / \mathrm{g}$ of fibers, respectively. The $\mathrm{pH}$ was kept constant at 10.5 by adding $\mathrm{NaOH} 0.5 \mathrm{M}$. The reaction time was approx. $40 \mathrm{~min}$. The carboxylic acid group content was quantified by conductometric titration. Homogenization of the oxidized fibers was performed with an ultra-turrax, at $24000 \mathrm{rpm}$ for $6 \mathrm{~min}$. The same homogenization process was applied to the four oxidized pulps. The concentration of the dispersion was 2 wt\%. 
ACS Sustainable Chemistry \& Engineering. Last update: 09.02.2018.

Table 1 Series of the produced CNF samples.

\begin{tabular}{|l|c|c|}
\hline Sample name & Pulping & TEMPO-mediated oxidation (mmol/g) \\
\hline BHS_T3.8 & HT+Soda & 3.8 \\
\hline BS_T3.8 & Soda & 3.8 \\
\hline BHS_T6.0 & HT+Soda & 6.0 \\
\hline BS_T6.0 & Soda & 6.0 \\
\hline
\end{tabular}

\section{$\underline{\text { Structural characterization }}$}

In order to assess the fibrillation degree, structures of $1 \mathrm{~mm} \times 10 \mathrm{~mm} \times 20 \mathrm{~mm}$ were printed directly on microscopy slides, using a Regemat3D printing unit. The structures were printed with a conical nozzle (size $0.58 \mathrm{~mm}$ ) and a flow speed of $3.0 \mathrm{~mm} / \mathrm{s}$. The structures were allowed to dry for one day at room temperature $\left(23^{\circ} \mathrm{C}\right)$.

Optical images from the microscopy slides with the formed films were acquired with an Epson Perfection scanner (version V750 PRO) in transmission mode, using 4800 dots per inch resolution. The translucency and skewness of the films (optical images) were assessed as described previously. ${ }^{31}$ The apparent number of particles observed on the optical images were quantified with the ImageJ program (version 1.50i). Six optical images of $4 \times 4 \mathrm{~mm}^{2}$ were assessed per each sample. The images were thresholded automatically and binarized. Noise particles that were less than $3000 \mu \mathrm{m}^{2}$ and had a circularity shape of less than 0.85 were excluded from the quantification.

The films were sputtered with a thin layer of gold (Agar Auto Sputter Coater). Ten Laser profilometry (LP) topography images were acquired from each film sample using a LP 
ACS Sustainable Chemistry \& Engineering. Last update: 09.02.2018.

(Lehmann, Lehman Mess-Systeme AG Baden-Dättwil, Germany). The lateral and z-resolution of the LP system was $1 \mu \mathrm{m}$ and $10 \mathrm{~nm}$, respectively. The size of the local areas was $1 \mathrm{~mm} \times 1$ $\mathrm{mm}$. The root-mean-square $(\mathrm{Sq})$ was quantified on the LP images. ${ }^{16}$

Scanning electron microscopy (SEM) was performed with a Hitachi SU3500 microscope, in secondary electron imaging (SEI) mode. Images were acquired with 100x magnification, using $5 \mathrm{kV}$ acceleration voltage. Additionally, a SEM assessment was performed with a LVfield emission-SEM (Zeiss Supra 55 VP), equipped with an Energy Dispersive Spectroscopy (EDS) unit to provide an elemental analysis. The acceleration voltage and the working distance were $10 \mathrm{kV}$ and $9.5 \mathrm{~mm}$, respectively.

Atomic force microscopy (AFM) imaging was performed on dried films of the CNF series. The films $\left(20 \mathrm{~g} / \mathrm{m}^{2}\right)$ were dried in Petri dishes and the AFM analysis was conducted on the bottom side of the films as described elsewhere ${ }^{16}$. The AFM equipment was a Veeco Multimode AFM (with Nanoscope V controller), Digital Instruments. The images $(2 \mu \mathrm{m} \times 2$ $\mu \mathrm{m})$ were acquired in ScanAsyst mode at room temperature.

\section{$\underline{3 D \text { printing }}$}

The nanocellulose gels ( $2 \mathrm{wt} \%$ ) were used as inks for 3D printing. The 3D printing was performed with a Regemat3D bioprinter (version 1.0), equipped with the Regemat3D Designer (version 1.8, Regemat3D, Granada, Spain). Grids having a diameter of $20 \mathrm{~mm}$ and a height of $2 \mathrm{~mm}$ were printed directly on microscopy slides for exemplification purposes. The target width of the printed tracks was $0.41 \mathrm{~mm}$. The target space between the tracks was 2 
ACS Sustainable Chemistry \& Engineering. Last update: 09.02.2018.

$\mathrm{mm}$. The inks were kept at room temperature $\left(25^{\circ} \mathrm{C}\right)$ for $24 \mathrm{~h}$ before printing. The flow speed was $3 \mathrm{~mm} / \mathrm{sec}$, using a $0.58 \mathrm{~mm}$ conical nozzle.

Digital models of an ear and a nose were used for exemplifying the printing performance of the bagasse inks. The 3D printing was performed with a flow speed of $2 \mathrm{~mm} / \mathrm{sec}$, using a $0.58 \mathrm{~mm}$ conical nozzle.

\section{Cytotoxicity}

In order to assess the cytotoxicity of the materials according to the ISO 10993-5:2009 Annex C, $0.3 \mathrm{~g}$ (dry matter) of CNF dispersions (0.4 wt\%) were poured in Petri dishes (X525 aseptic $120 \times 120 \times 15.8 \mathrm{~mm}$ from Fisher Scientific) and frozen at $-30{ }^{\circ} \mathrm{C}$ during 24 hours. The freezedrying was performed with a Biobase BK-FD12S. The cytotoxicity potential of the CNF gels was determined using the MTT based method ISO 10993-5:2009 Annex C, which is the standard used for biological evaluation of medical device products.

The CNF was extracted at $37 \pm 1^{\circ} \mathrm{C}$ for $24 \pm 2 \mathrm{~h}$ in Eagle's Minimum essential medium $1 \mathrm{X}$ with non-essential amino acids (Gibco Life Technologies) and sodium pyruvate (GE Healthcare HyClone), supplemented with $5 \%$ (v/v) Fetal Bovine Serum (Gibco Life Technologies), 4 mM L-glutamine (Lonza), $100 \mathrm{IU} / \mathrm{ml}$ penicillin and $100 \mu \mathrm{g} / \mathrm{ml}$ streptomycin (Gibco Life Technologies) using a ratio of $0.1 \mathrm{~g} / \mathrm{mL}$.

Cytotoxicity was determined using two concentrations of the CNF extract (100\% and $50 \%$ ) together with positive control (latex) and negative control extracts. All dilutions were performed with blank (extraction vehicle not containing the test item but subjected to 
ACS Sustainable Chemistry \& Engineering. Last update: 09.02.2018.

conditions identical to those to which the test item was subjected to during extraction). Each extract solution was added to 6 replicate wells, containing a subconfluent monolayer of cells (cell line L929, mouse fibroblast). Blanks were also placed in 6 wells on each side of the 96 well plate to confirm that no systematic cell seeding errors occurred, as well as to serve as a $100 \%$ measure of cell viability. After the extracts were added the plate was incubated for 24 hours at $37 \pm 1{ }^{\circ} \mathrm{C}$ in $5 \pm 1 \% \mathrm{CO}_{2}$. Following incubation, the extracts were removed and $\mathrm{MTT}$ (Sigma-Aldrich) solution was added to each well and the cells were incubated for 2 hours at $37 \pm 1^{\circ} \mathrm{C}$ in $5 \pm 1 \% \mathrm{CO}_{2}$. After incubation, the MTT solution was removed and 2-propanol (Fischer Chemicals) was added to each well. The plate was then shaken rapidly until the formazan from the cells had been extracted and formed a homogeneous solution on which the absorbance was measured at $570 \mathrm{~nm}$ (reference wavelength $650 \mathrm{~nm}$ ) using Synergy 2 (Biotek).

\section{$\underline{\text { Results and discussion }}$}

\section{Chemical composition of bagasse and pulps}

The hydrothermal treatment of sugarcane bagasse has proven to be suitable to extract hemicelluloses components in a way that can be used for conversion to different products, ${ }^{32,33}$ without altering the capacity of the material to be later delignified by different processes. The soda process, using aqueous sodium hydroxide solution as cooking liquor, is usually used to produce chemical pulps from materials low in lignin, which are easily pulped like non-wood plants, as is the case of this study (Table 2). The HT + Soda pulp have a chemical composition that is characteristic for HT extracted and Soda delignified bagasse pulps (Table 2)..$^{34,35}$ 
ACS Sustainable Chemistry \& Engineering. Last update: 09.02.2018.

Table 2 Chemical composition of the untreated bagasse and of bagasse pulps (\% oven dried, od)

\begin{tabular}{|l|c|c|c|}
\hline & Untreated bagasse & & \\
& $(\% \circ)$ & Soda pulp (\%od) & HT+Soda pulp (\%od) \\
\hline Screened yield & -- & 51.5 & 52.6 \\
\hline Glucans & $43.1 \pm 0.26$ & $66.77 \pm 0.33$ & $82.41 \pm 0.08$ \\
\hline Xylans & $23.8 \pm 0.08$ & $27.52 \pm 0.1$ & $13.17 \pm 0.1$ \\
\hline Arabinans & $1.66 \pm 0.02$ & $0.95 \pm 0.03$ & $0.28 \pm 0.01$ \\
\hline Acetyl groups & $1.70 \pm 0.07$ & -- & -- \\
\hline Lignin & $21.3 \pm 0.52$ & $1.80 \pm 0.15$ & $4.33 \pm 0.08$ \\
\hline Extractives & $4.80 \pm 0.30$ & -- & -- \\
\hline Ash & $1.45 \pm 0.10$ & -- & 13.45 \\
\hline Hemicelluloses & 27.16 & 28.47 & - \\
\hline
\end{tabular}

TEMPO-mediated oxidation and CNF morphology

TEMPO-mediated oxidation has been widely used to produce CNF from various sources, including bagasse. ${ }^{36}$ The oxidation with $\mathrm{NaClO}$ introduces charges to the fibers, which facilitate the electrostatic repulsion between the fibrils in the fiber wall structure. The higher the level of oxidation, the higher the charge that is introduced and the easier the nanofibrillation of the material, i.e. the higher the yield of CNF. ${ }^{37}$ In this work, two levels of $\mathrm{NaClO}$ were applied for comparison purposes, i.e. 3.8 and $6.0 \mathrm{mmol} / \mathrm{g}$ of cellulose.

The evolution of the kappa number, representing lignin content in pulps, is shown in Table 3. The relative percentages of extraction of lignin between the autoclave extraction and the oxidation stages were $29 \%$ and $73 \%$ for the BS pulp and $62 \%$ and $87 \%$ for the BHS pulp. 
ACS Sustainable Chemistry \& Engineering. Last update: 09.02.2018.

The material subjected to hydrothermal treatment is more porous (due to the spaces left by the hemicelluloses) and therefore the alkali in the alkaline treatment (autoclaving) and the $\mathrm{NaClO}$ in the TEMPO treatment can access the fiber structure more easily, thus extracting more lignin.

Table 3 Evolution of Kappa number showing the delignification in each stage. The measurements were undertaken for the pulps, after the alkaline washing $(3 \mathrm{x} \mathrm{NaOH}$ and autoclaved) and after the TEMPO-mediated oxidation $(6.0 \mathrm{mmol} \mathrm{NaClO} / \mathrm{g})$.

\begin{tabular}{|c|cc|}
\hline Samples & Kappa number & $\begin{array}{c}\text { Relative extraction } \\
\text { of lignin (\%) }\end{array}$ \\
\hline $\mathrm{BS}$ & 9.3 \\
\hline $\mathrm{BS}+3 \times \mathrm{NaOH}$ & 6.6 & 29 \\
\hline $\mathrm{BS}+3 \times \mathrm{NaOH}+\mathrm{T} 6.0$ & 1.8 & 73 \\
\hline $\mathrm{BHS}$ & 29.9 \\
\hline $\mathrm{BHS}+3 \times \mathrm{NaOH}$ & 11.5 & 62 \\
\hline $\mathrm{BHS}+3 \times \mathrm{NaOH}+\mathrm{T} 6.0$ & 1.5 & 87 \\
\hline
\end{tabular}

The carboxylic acid group content for the four produced series of CNF is given in Error! Reference source not found.. The higher amount of $\mathrm{NaClO}$ clearly affect the level of oxidation of the two bagasse fibers, increasing the carboxylic acid content from roughly 1 to $1.6 \mathrm{mmol} / \mathrm{g}$. However, there is also a significant difference between the two pulps, BS-series being less oxidized than the BHS-series. It has been reported before that a higher xylan content has a significant negative effect on the oxidation rate. ${ }^{38}$ The BHS sample contains less hemicelluloses compared to the BS series (about 13.5 and 28.5 respectively). Additionally, TEMPO-mediated oxidation is regioselective for the primary hydroxyl groups of polysaccharides, ${ }^{39}$ i.e. attacking only the C6-position in the anhydroglucose unit (AGU) of 
ACS Sustainable Chemistry \& Engineering. Last update: 09.02.2018.

cellulose. Xylan has two secondary hydroxyl groups but no primary ones and is therefore not functionalized by TEMPO-mediated oxidation. ${ }^{40}$

The T6.0 series are more oxidized and thus yield a larger fraction of nanofibrils, which apparently increases the viscosity of the gels. The T6.0 series do not flow (Figure 1). This is exemplified in the right panel where the containers are placed upside down without causing any major flow of the CNF, compared to the T3.8 series.

Table 4 Carboxylic acid group content of the CNF series, the roughness of the corresponding CNF films and the number of particles quantified on optical images. The average values are given \pm 1 standard deviation.

\begin{tabular}{|l|c|c|c|}
\hline Sample name & $\begin{array}{c}\text { Carboxylic acid groups } \\
(\mu \mathrm{mol} / \mathrm{g})\end{array}$ & $\begin{array}{c}\text { LP roughness } \\
(\mu \mathrm{m})\end{array}$ & $\begin{array}{r}\text { Number of apparent } \\
\text { silica particles } \\
\left(\# / \mathrm{mm}^{2}\right)\end{array}$ \\
\hline BHS_T3.8 & $1150 \pm 10$ & $2.66 \pm 0.16$ & $0.1 \pm 0.1$ \\
\hline BS_T3.8 & $1044 \pm 1$ & $2.04 \pm 0.21$ & $0.5 \pm 0.2$ \\
\hline BHS_T6.0 & $1670 \pm 5$ & $0.87 \pm 0.15$ & $0.5 \pm 0.2$ \\
\hline BS_T6.0 & $1444 \pm 19$ & $0.99 \pm 0.07$ & $1.7 \pm 0.4$ \\
\hline
\end{tabular}




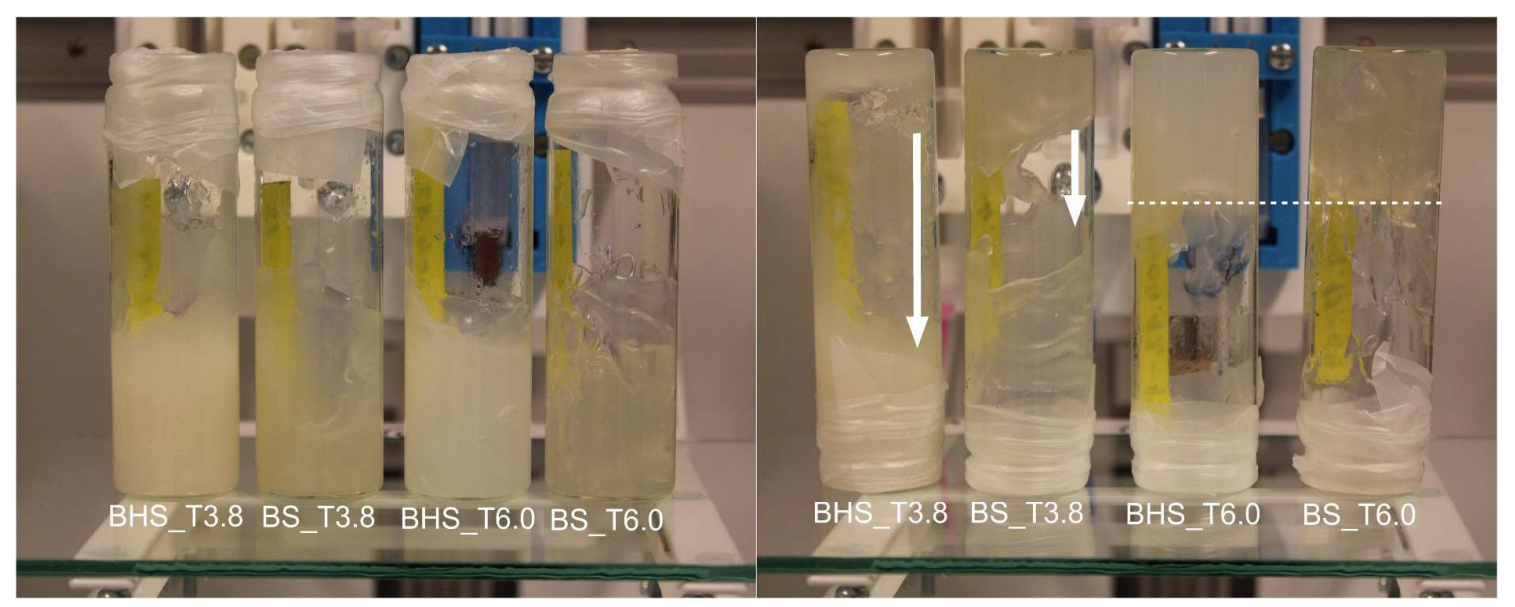

Figure 1 Bagasse CNF. Left) The four series of produced CNF. Right) The same vials placed up/down. The flow (white arrows) of the samples BHS_T3.8 and BS_T3.8 is exemplified. The dotted line indicates the border of the nanocellulose samples, which do not show signs of flow.

The nanofibrillation degree can be easily assessed by quantifying the translucency of the printed films (Figure 2). The higher the translucency, the higher the nanofibrillation. This is also confirmed by the skewness values of the translucency distribution ${ }^{31}$ and by the roughness assessed by laser profilometry (Table 4). The roughness at the assessed scale is affected by the residual fibres ${ }^{16}$. The lesser the fraction of residual fibers, the higher the number of nanofibrils, and the smoother the films. This is confirmed by the SEM images of the four series (Figure 2). Additionally, the BS series shows significantly larger amount of particles (Table 4), which are presumptively silica particles from the bagasse parenchyma cells. Figure 3 exemplifies the nano-morphology of the nanofibrils. Although, in this case, it is demanding to estimate the length of the nanofibrils because of network entanglement, the width is clearly in the nanometer scale. The nanofibrillated structure is relatively homogeneous, and composed of nanofibrils with diameters of roughly less than $20 \mathrm{~nm}$ and 
ACS Sustainable Chemistry \& Engineering. Last update: 09.02.2018.

lengths in the micrometer-scale (Figure 3) and have thus similar morphology as the CNFs produced with TEMPO-mediated oxidation from a variety of sources, softwood, hardwood, corn husks, oat hulls. ${ }^{8,11,41,42}$

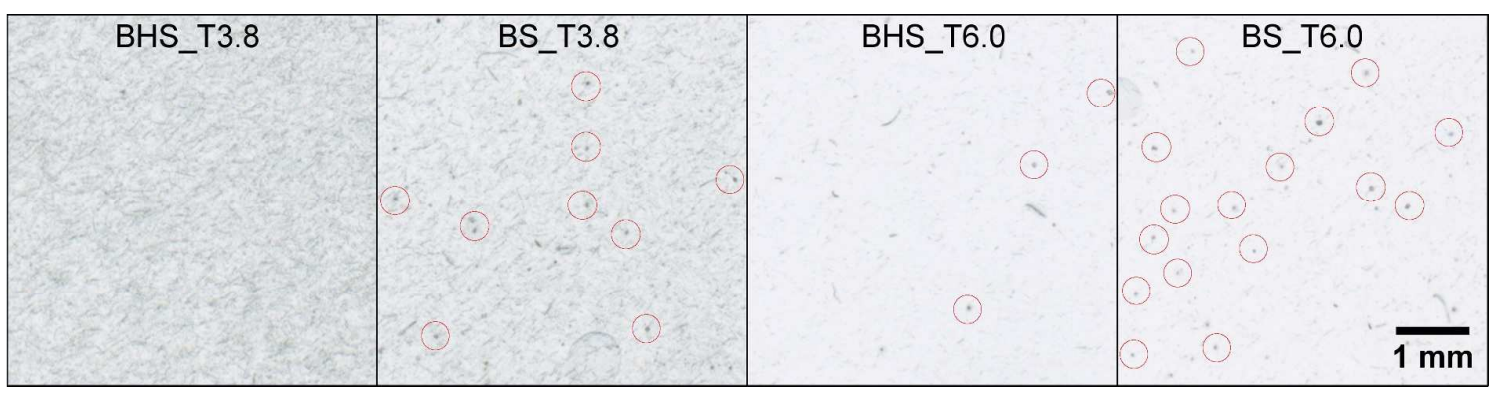
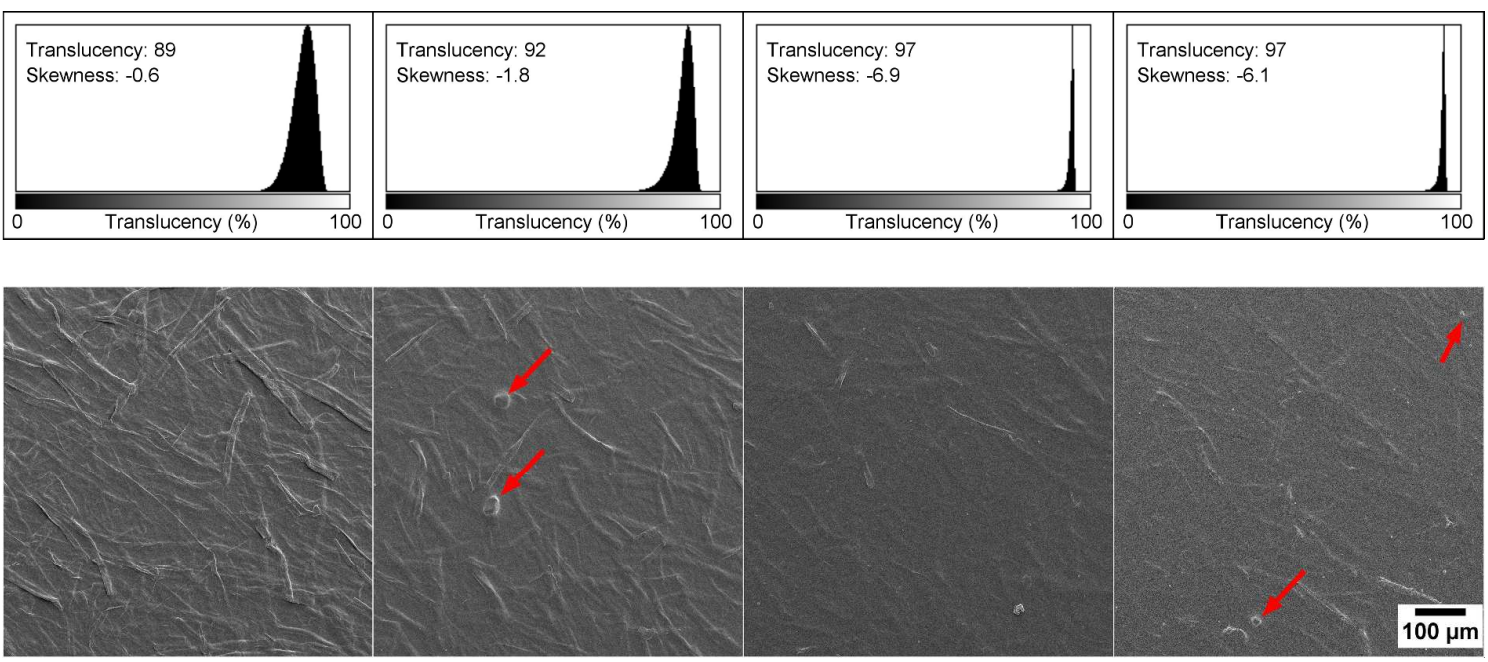

Figure 2 Characterization of films. Upper panel) Optical images acquired with a desktop scanner in transmission mode, note the larger occurrence of round particles observed in the BS samples (red circles). Middle panel) Histogram of the scanner images showing the light transmittance distribution. Lower panel) The corresponding SEM images, exemplifying some of the particles observed in the scanner images (red arrows). 


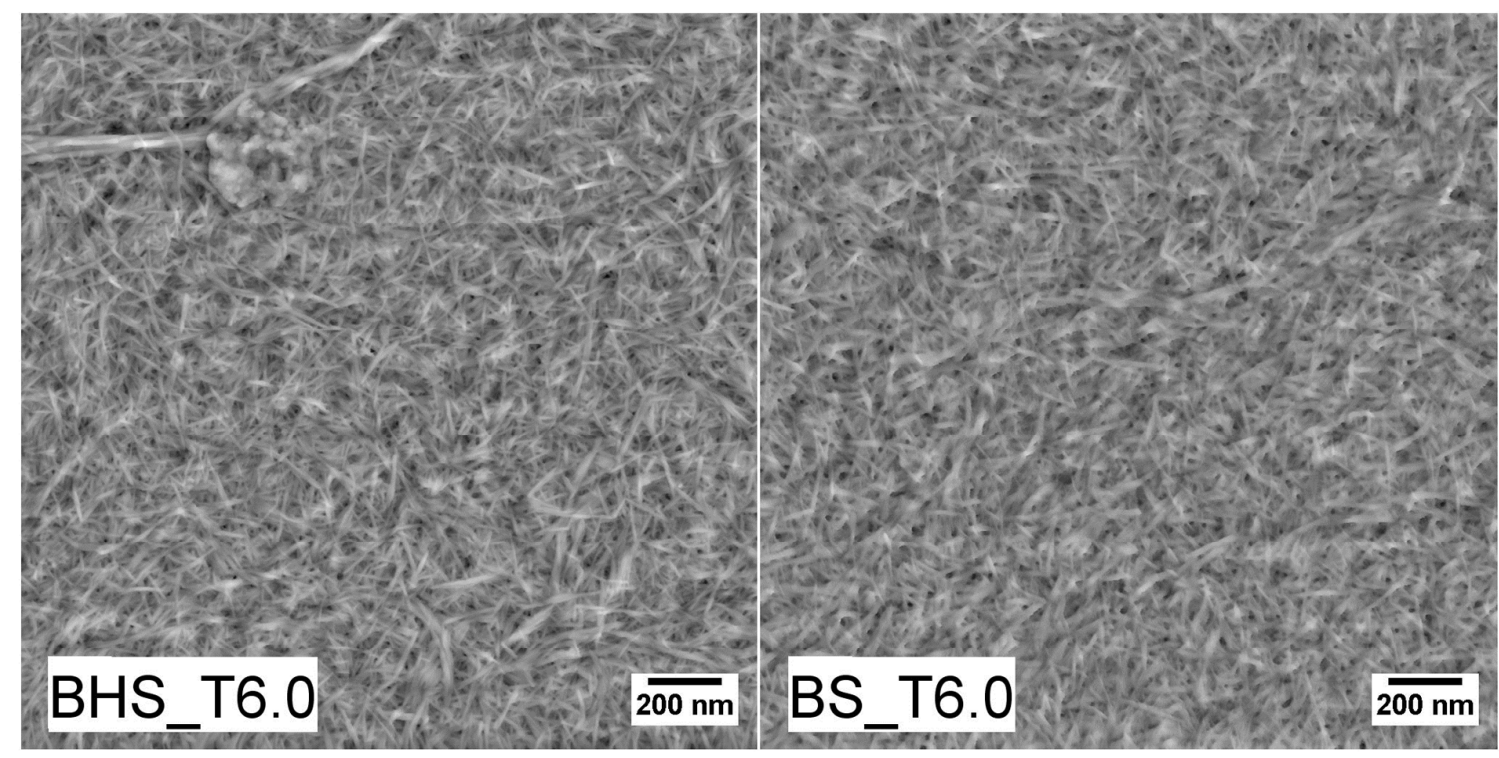

Figure 3 AFM images of samples BHS_T6.0 and BS_T6.0.

\section{Assessment of cytotoxicity}

The inks developed in this work are based on bagasse, which is an agro-industrial residue.

Such residues may be contaminated with microorganisms and toxins, which may limit their application in high-value products such as 3D printing inks. As a first step regarding the suitability of the bagasse-based CNFs as inks for 3D printing, the cytotoxicity was assessed following concrete standards for testing materials intended for biomedical devices. The cytocompatibility of the material is a very important factor if it will be used in connection with cells. If the material is assessed as cytotoxic it cannot be used in contact with the human body or living organisms. The cell viability of the four series is given in Figure 4 and Figure 5.

The viability of L929 mouse fibroblasts exposed to extract 100\% from the device should be $\geq 70 \%$ in an MTT assay to pass as a non-cytotoxic medical device (according to ISO 109935:2009 Annex C). The BS_T6.0 100\% is the only sample that is cytotoxic. Additionally, the 
ACS Sustainable Chemistry \& Engineering. Last update: 09.02.2018.

data indicate that the cytotoxicity (survival of cells) is better in the BHS samples. There is no major difference between BHS_T3.8 100\% and BHS_T6.0 100\%. All other test items were considered non-cytotoxic. Importantly, the BS_T6.0 series had similar Kappa number as the BHS_T6.0 series (Table 3). Hence, it is unlikely that the lignin is causing the cytotoxic effect detected for the BS series, which clarifies an important aspect not previously taken into account.

The BHS series had a relatively small fraction of hemicelluloses, compared to the BS series (Table 2). Previously, a correlation has been demonstrated between the concentration of formic acid and chromosomal aberrations, i.e. frequency of micronuclei, apoptotic cells, and necrotic cells in vitro. ${ }^{43}$ The larger fraction of xylans encountered in the BS series may have contributed to the formation of acids with a potential cytotoxic effect. However, we have previously demonstrated that pulps differing in xylan content and treated with $3.8 \mathrm{mmol} / \mathrm{g}$ $\mathrm{NaClO}^{8}$ were not cytotoxic ${ }^{44}$. Additionally, although the hydrothermal treatment deacetylates xylans and generates acetic acid, the BHS series were considered cytocompatible. 
ACS Sustainable Chemistry \& Engineering. Last update: 09.02.2018.

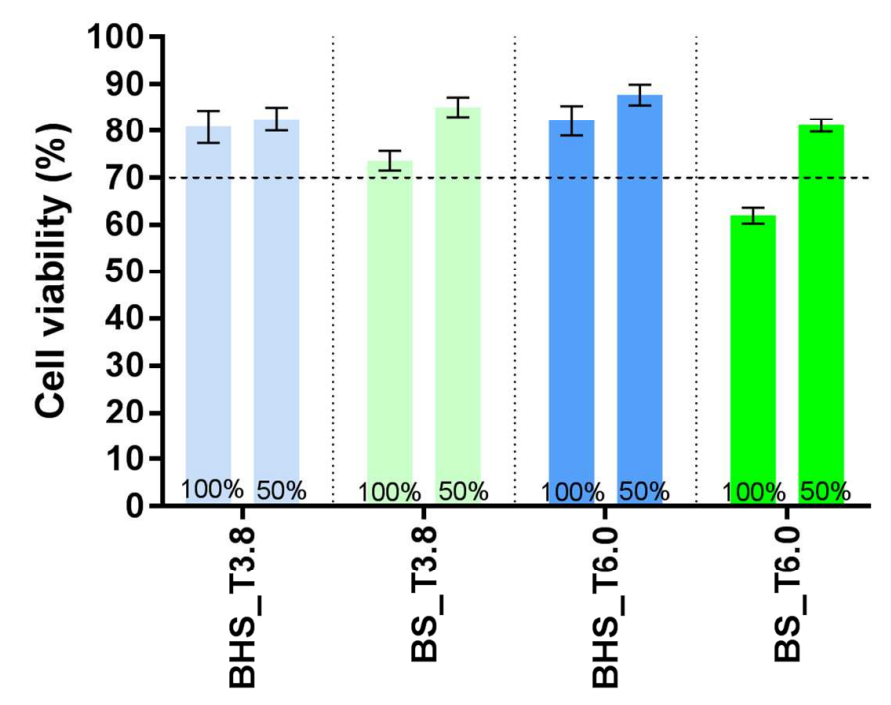

Figure 4 Cytotoxicity determination of CNF samples. $70 \%$ viability and below is considered cytotoxic according to ISO 10993-5:2009 Annex C. 

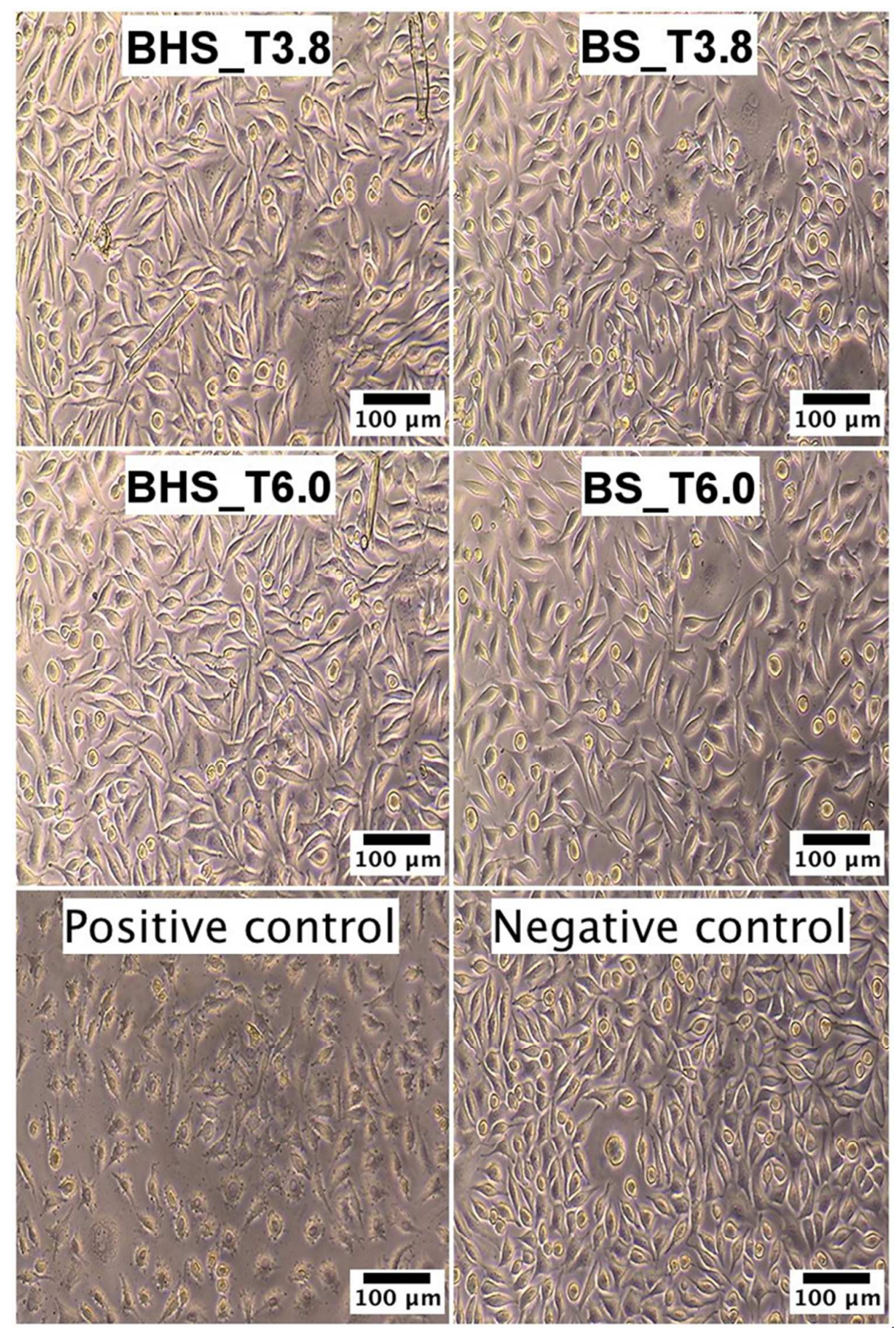

Figure 5 Light microscopy with phase contrast images showing the cell morphology and cell

number after 24 hours incubation of $100 \%$ extracts. The positive control is killing all cells and the negative control is not killing any cells. It is observed that the BS_T6.0 series has less cell survival than the negative control. 
ACS Sustainable Chemistry \& Engineering. Last update: 09.02.2018.

In the present study, the cytotoxic effect is strictly detected only for the BS_T6.0 series, although the cytotoxic trend is also evident for the BS_T3.8 series. There are various studies of the cytotoxicity of sugarcane bagasse, which seems to be caused by silica particles. ${ }^{45-49}$ Silica is found in the parenchyma cells of bagasse. It is worthy of notice that the image of the BS sample shows greater number of particles (Figure 2,

Table 4), which are silica particles as confirmed by EDS (Figure 6).
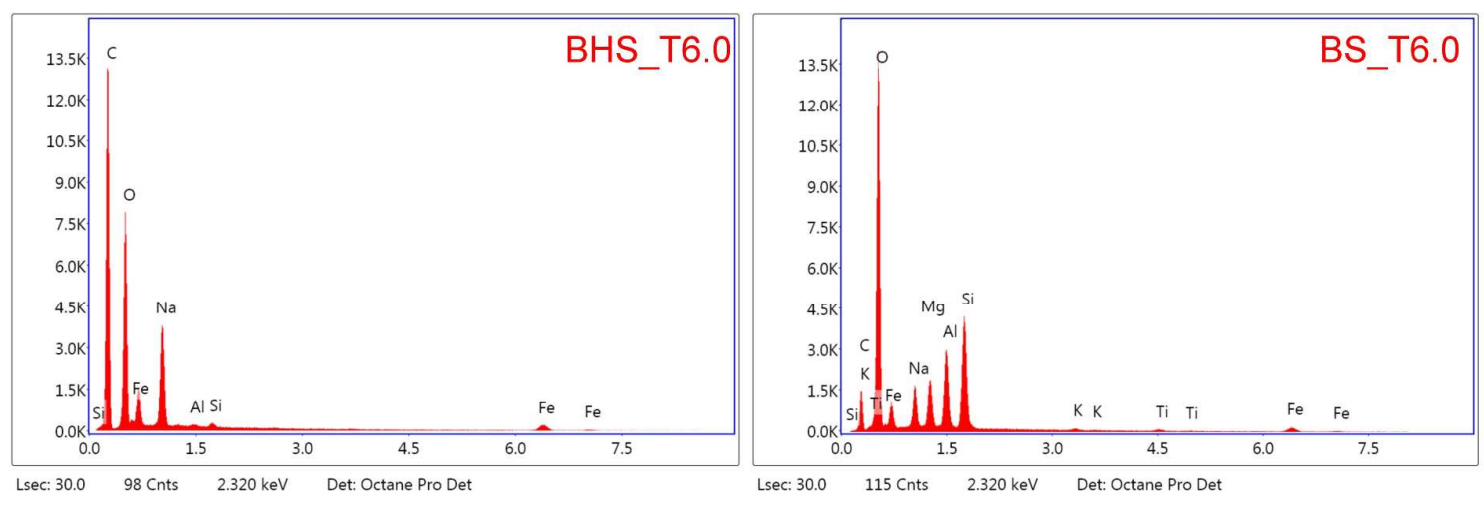

Figure 6 Determination of silica by EDS. Note the major occurrence of silicon observed in the BS sample, compared to the BHS sample.

Compared to the BS series, the pulps subjected to hydrothermal processing (BHS) passed through more washing stages, where the parenchyma cells could have passed the filters and were thus removed from the pulp. Additionally, the cytotoxicity assessment shows that the oxidation of the BS sample has an effect (Figure 4). TEMPO-mediated oxidation facilitates the de-construction of the fiber wall, which may also have induced the release of silica particles. The silica particles do not form an interlaced network and are thus presumptively released into the extract that is used for the cytotoxicity assay. The cytotoxicity effect is evidenced in the BS sample (Figure 4), since it seems to have a higher load of silica particles, 
ACS Sustainable Chemistry \& Engineering. Last update: 09.02.2018.

compared to the BHS pulp (Figure 2). There are precedents about the elimination of cane bagasse toxicity by different methods. ${ }^{50,51}$ In this work, the beneficial effect of the hydrothermal and alkaline treatments to reduce the cytotoxicity of bagasse CNF has been demonstrated. Importantly, these findings also emphasize the necessity of characterizing CNFs properly, considering chemical, structural and biological aspects.

\section{$\underline{3 D}$ Printing}

It is expected that the structuring of biomedical devices having tailor-made functionality will be facilitated by 3D printing technology, because of the possibilities to design and modify a porous structure suitable for specific cells and tissues. There are already a series of studies pointing in this direction. ${ }^{23,52}$ Nanocelluloses (including CNF and cellulose nanocrystals) seem to be promising nanomaterials in this respect. ${ }^{24,53-57}$ This is mainly due to three reasons; i) nanocelluloses are thixotropic materials, which is beneficial for 3D printing, ii) nanocelluloses can form networks with a structure that resembles the extracellular matrix and iii) nanocelluloses are non-cytotoxic, allowing cell proliferation and differentiation. Specifically, TEMPO CNF fulfills these requirements, as has been demonstrated recently. ${ }^{24,30,58}$

In this study, we have demonstrated that non-cytotoxic TEMPO CNF can be obtained from bagasse. Additionally, it has been reported previously that TEMPO CNF is viscous and shows clear signs of shear thinning behavior. ${ }^{24,27}$ The BHS-T3.8 and BS-T6.0 are apparently the least and most viscous materials, respectively. As expected, the viscosity and the shear thinning affect the ink extrusion and the deposition during 3D printing. ${ }^{22}$ The BS-T6.0 sample yields the best print resolution and stability, i.e. the gel does not flow laterally when deposited on a surface and maintains a well-differentiated track structure (Figure 7). Although the 
ACS Sustainable Chemistry \& Engineering. Last update: 09.02.2018.

BHS_T3.8 sample is suitable for 3D printing, the 3D constructs have a limited print fidelity, i.e. the printed tracks flow laterally and merge with neighboring structures. This may be related to the degree of fibrillation of this sample, which is relatively low, as exemplified in Figure 2. The sample BHS_T3.8 contains a relatively large amount of residual fibers, which are clearly observed in the optical and SEM images (Figure 2) and quantified by laser profilometry (Table 4).

Note that the print quality is improved when the material is more oxidized (Table 4), more nanofibrillated, and thus apparently more viscous (compare the T3.8 series with the respective T6.0 series). This is observed for both the BHS and the BS series. However, the degree of oxidation and fibrillation does not explain the lower print quality of the BHS_T6.0 sample (carboxylic acid groups: $1.670 \mathrm{mmol} / \mathrm{g}$ ) compared to the BS_T3.8 sample (carboxylic acid groups: $1.044 \mathrm{mmol} / \mathrm{g}$ ). It has been reported that viscosity, rheology, and mechanical properties of CNF gels are affected by the hemicellulose content. ${ }^{38,59}$ Removal of xylan from pulp prior to TEMPO oxidation and CNF production, resulted in less network swelling, lower viscosity, and a weaker CNF gel structure. ${ }^{38}$ The addition of hemicellulose to CNF resulted in increased Young's modulus. ${ }^{59}$ The mechanism by which the rheology is influenced may include alteration of the mechanical entanglement of fibrils and hemicellulose polymers, and alteration of hydrogen bonds between hemicellulose and chemical structures in the fibrils. The BS pulp contained $27.5 \%$ of xylan compared to $13.2 \%$ in the BHS pulp (Table 2). The larger amounts of xylan in the BS series can thus be one cause of their apparently higher viscosity and their better print quality. 
ACS Sustainable Chemistry \& Engineering. Last update: 09.02.2018.

As an attempt to improve the print quality of the BHS_T3.8 series the concentration of the CNF gel was increased to $2.6 \%$ by centrifugation. It is known that an increase in concentration leads to more viscous CNF gels. ${ }^{60}$ The concentration of $2.6 \mathrm{wt} \%$ of the sample BHS_T3.8 is expected to be above the estimated percolation threshold for similar TEMPO CNFs. ${ }^{61}$ Thus, the increase of concentration from 2.0 to $2.6 \mathrm{wt} \%$ is assumed to increase the viscosity by promoting the entanglement of nanofibrils in the network. For exemplification purposes, a nose and an ear were printed using the BHS_T3.8 (concentration 2.6 wt\%) and BHS_T6.0 inks (concentration 2.0 wt\%). Both printing operations were satisfactory and the results look promising for using the inks for 3D printing (Figure 8). As expected, the best print result was obtained with the BS_T6.0 ink, confirming the printing of the grid structures (Figure 7). The 3D objects were more delineated and apparently stable. However, the BS_T6.0 3D printed objects were also rougher, compared to the BHS-series. This characteristic detail was most probably caused by the low lateral flowability of the BS_T6.0 ink (see also Figure 7), which does not permit a lateral diffusion of ink, thus limiting the smoothening of the object surface.

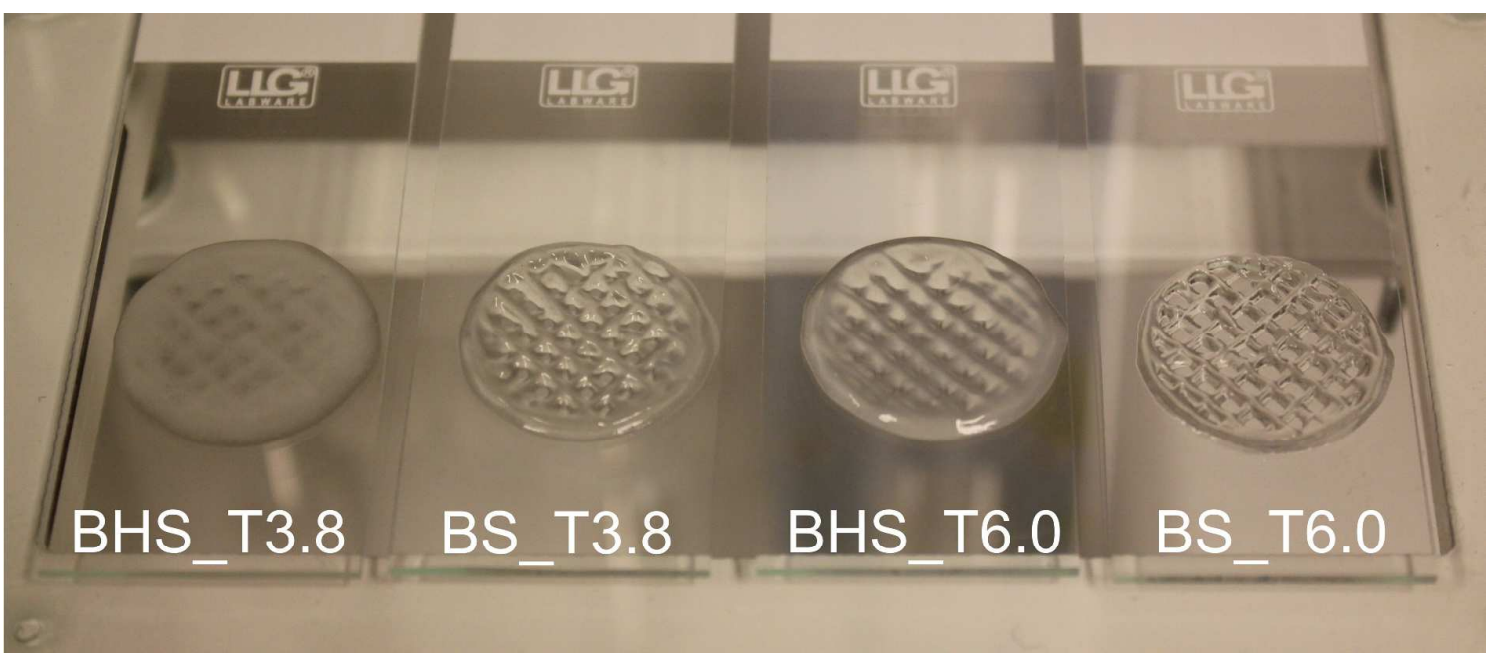

Figure 7 3D Printing of the bagasse CNF inks. 
ACS Sustainable Chemistry \& Engineering. Last update: 09.02.2018.

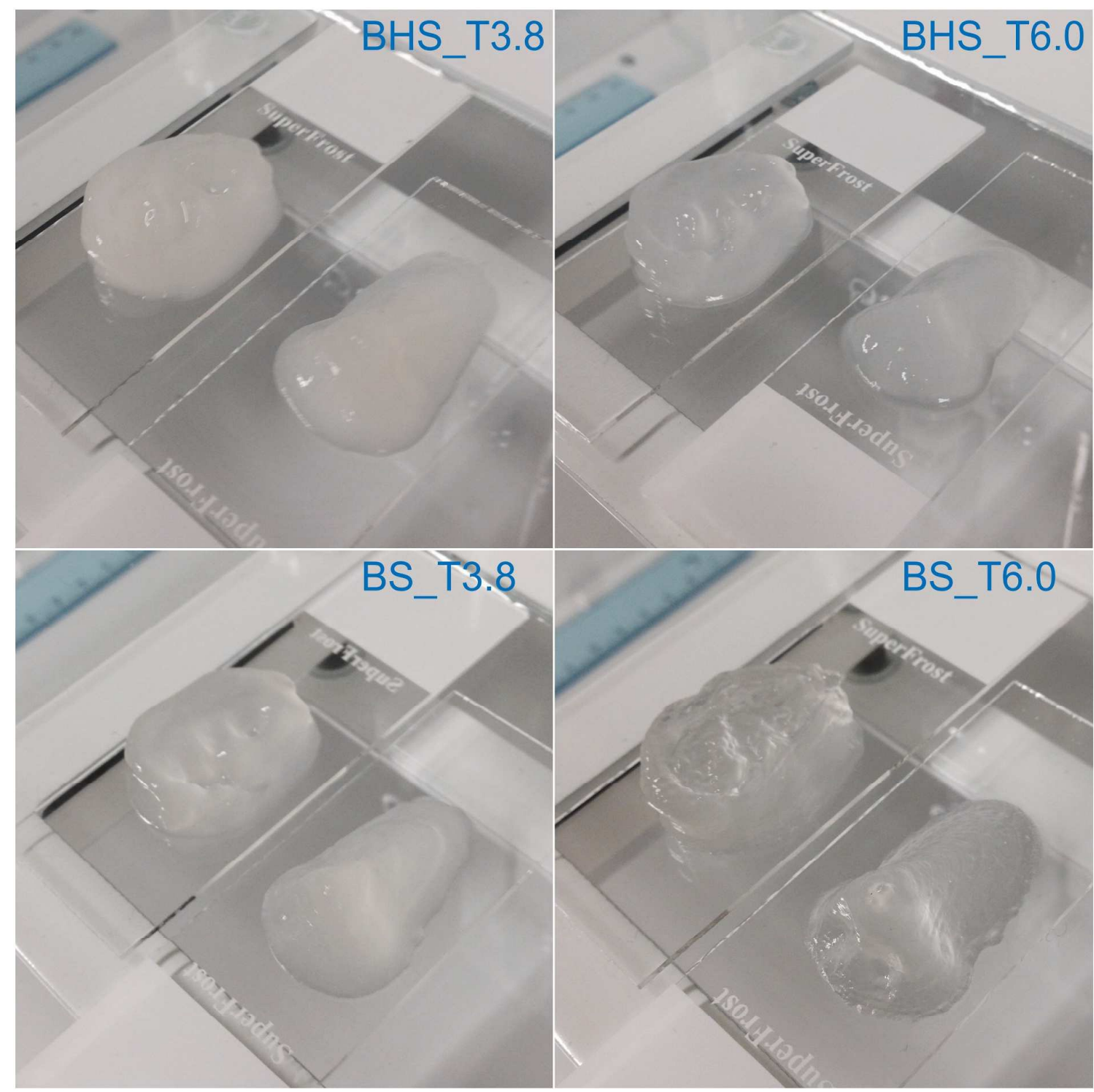

Figure 8 3D printing of nose and ear scaffolds with the inks BHS_T3.8 (concentration 2.6 wt\%), BHS_T6.0 (concentration 2.0 wt\%), BS_T3.8 (concentration 2.0 wt\%), BS_T6.0 (concentration $2.0 \mathrm{wt} \%$ ).

Given that the BS series print better (Figure 7 and Figure 8), and assuming that silica is the cause of the cytotoxicity, a more intensive depithing could be tried. Bagasse pith was removed in two stages, by mechanical treatment and screening. Two passes through the refiner could be applied to further open the bagasse structure, thus facilitating the 
ACS Sustainable Chemistry \& Engineering. Last update: 09.02.2018.

separation of the fibrovascular bundles from the parenchymal cells. This would also shrink the particle size, which would accelerate the pulping. The elimination of parenchyma also supposes the elimination of other minerals and extractive substances, which could also contribute to cytotoxicity.

Considering the appropriate nanofibrillation and the lack of cytotoxicity of the BHS series (hydrothermal and alkaline treatment), we have demonstrated that a low-value agroindustrial residue (bagasse) can be converted into a high-value product (inks for 3D printing). The inks have potential in 3D printing and may be used for structuring biomedical devices, e.g. wound dressings, scaffolds for drug testing and for tissue engineering. The non-cytotoxic materials (BHS samples) assessed in this study seem to be good candidates for such applications. However, there is some additional biological evaluation that needs to be performed if the materials should be used as medical devices, and of most importance in this respect is to test for skin irritation and skin sensitization, which will be performed in future studies.

\section{Acknowledgement}

This work has been funded by the ValBio-3D project (Grant ELAC2015/T03-0715 Valorization of residual biomass for advanced 3D materials; Research Council of Norway, Grant no. 271054). The authors acknowledge the Consejo Nacional de Investigaciones Científicas y Técnicas (CONICET) and the Universidad Nacional de Misiones (Argentina) for the financial support. Thanks to Yingda Yu (NTNU) for the EDS analysis and Mirjana Filipovic, Ingebjørg Leirset and Anne Marie Reitan (RISE PFI) for laboratory analyses. 
ACS Sustainable Chemistry \& Engineering. Last update: 09.02.2018.

\section{References}

(1) CONAB. Campaña 2015 / 2016.

(2) Vallejos, M. E.; Felissia, F. E.; Area, M. C. Hydrothermal treatments applied to agroand forest-industrial waste to produce high added-value compounds. BioResources 2017, 12 (1), 2058-2080.

(3) Matsushita, Y. Conversion of technical lignins to functional materials with retained polymeric properties. J. Wood Sci. 2015, 61 (3), 230-250.

(4) Peña, C. G.; Mitrani, R. B.; Correa, J. L.; Cadenas, G. A.; Munilla, M. H. Capítulo 2.2. Bagazo. In Manual de los Derivados de la Caña de Azúcar; Instituto Cubano de Investigaciones de los Derivados de la Caña de Azúcar, ICIDCA, 2000.

(5) Mandal, A.; Chakrabarty, D. Isolation of nanocellulose from waste sugarcane bagasse (SCB) and its characterization. Carbohydr. Polym. 2011, 86 (3), 1291-1299.

(6) Vallejos, M. E.; Felissia, F. E.; Area, M. C.; Ehman, N. V.; Tarrés, Q.; Mutjé, P. Nanofibrillated cellulose (CNF) from eucalyptus sawdust as a dry strength agent of unrefined eucalyptus handsheets. Carbohydr. Polym. 2016, 139, 99-105.

(7) Ehman, N. V; Tarrés, Q.; Delgado-Aguilar, M.; Vallejos, M. E.; Felissia, F.; Area, M. C.; Mutjé, P. From pine sawdust to cellulose nanofibres. Cellul. Chem. Technol. 2016, 50 (3-4), 361-367.

(8) Syverud, K.; Chinga-Carrasco, G.; Toledo, J.; Toledo, P. G. A comparative study of Eucalyptus and Pinus radiata pulp fibres as raw materials for production of cellulose nanofibrils. Carbohydr. Polym. 2011, 84 (3), 1033-1038.

(9) Tarrés, Q.; Ehman, N. V.; Vallejos, M. E.; Area, M. C.; Delgado-Aguilar, M.; Mutjé, P. Lignocellulosic nanofibers from triticale straw: The influence of hemicelluloses and 
ACS Sustainable Chemistry \& Engineering. Last update: 09.02.2018.

lignin in their production and properties. Carbohydr. Polym. 2017, 163, 20-27.

(10) García, A.; Gandini, A.; Labidi, J.; Belgacem, N.; Bras, J. Industrial and crop wastes: A new source for nanocellulose biorefinery. Ind. Crops Prod. 2016, 93, 26-38.

(11) Valdebenito, F.; Pereira, M.; Ciudad, G.; Azocar, L.; Briones, R.; Chinga-Carrasco, G. On the nanofibrillation of corn husks and oat hulls fibres. Ind. Crops Prod. 2017, 95, 528534.

(12) Winuprasith, T.; Suphantharika, M. Microfibrillated cellulose from mangosteen (Garcinia mangostana L.) rind: Preparation, characterization, and evaluation as an emulsion stabilizer. Food Hydrocoll. 2013, 32 (2), 383-394.

(13) Saito, T.; Nishiyama, Y.; Putaux, J. L.; Vignon, M.; Isogai, A. Homogeneous suspensions of individualized microfibrils from TEMPO-catalyzed oxidation of native cellulose. Biomacromolecules 2006, 7 (6), 1687-1691.

(14) Wågberg, L.; Decher, G.; Norgren, M.; Lindström, T.; Ankerfors, M.; Axnäs, K. The Build-Up of Polyelectrolyte Multilayers of Microfibrillated Cellulose and Cationic Polyelectrolytes. Langmuir 2008, 24 (3), 784-795.

(15) Liimatainen, H.; Visanko, M.; Sirviö, J. A.; Hormi, O. E. O.; Niinimaki, J. Enhancement of the Nanofibrillation of Wood Cellulose through Sequential Periodate-Chlorite Oxidation. Biomacromolecules 2012, 13 (5), 1592-1597.

(16) Chinga-Carrasco, G.; Syverud, K. Pretreatment-dependent surface chemistry of wood nanocellulose for pH-sensitive hydrogels. J. Biomater. Appl. 2014, 29 (3), 423-432.

(17) Li, J.; Wei, X.; Wang, Q.; Chen, J.; Chang, G.; Kong, L.; Su, J.; Liu, Y. Homogeneous isolation of nanocellulose from sugarcane bagasse by high pressure homogenization. Carbohydr. Polym. 2012, 90 (4), 1609-1613.

(18) Wang, Q.; Zhang, Y. H. Extraction of Nanocellulose from Sugarcane Bagasse. Appl. 
ACS Sustainable Chemistry \& Engineering. Last update: 09.02.2018.

Mech. Mater. 2014, 633-634, 550-553.

(19) Wulandari, W. T.; Rochliadi, A.; Arcana, I. M. Nanocellulose prepared by acid hydrolysis of isolated cellulose from sugarcane bagasse. IOP Conf. Ser. Mater. Sci. Eng. 2016, 107, 12045.

(20) Kumar, A.; Negi, Y. S.; Choudhary, V.; Bhardwaj, N. K. Sugarcane Bagasse: A Promising Source for the Production of Nanocellulose. J. Polym. Compos. 2014, 2 (3), 23-27.

(21) Hassan, E. A.; Hassan, M. L.; Oksman, K. Improving bagasse pulp paper sheet properties with microfibrillated cellulose isolated from xylanase-treated bagasse. Wood Fiber Sci. 2011, 43 (1), 76-82.

(22) Jose, R. R.; Rodriguez, M. J.; Dixon, T. A.; Omenetto, F.; Kaplan, D. L. Evolution of Bioinks and Additive Manufacturing Technologies for 3D Bioprinting. ACS Biomater. Sci. Eng. 2016, 2 (10), 1662-1678.

(23) Hong, N.; Yang, G.-H.; Lee, J.; Kim, G. 3D bioprinting and its in vivo applications. J. Biomed. Mater. Res. Part B Appl. Biomater. 2017.

(24) Rees, A.; Powell, L. C.; Chinga-Carrasco, G.; Gethin, D. T.; Syverud, K.; Hill, K. E.; Thomas, D. W. 3D Bioprinting of Carboxymethylated-Periodate Oxidized Nanocellulose Constructs for Wound Dressing Applications. Biomed Res. Int. 2015, 2015, 1-7.

(25) Falconnet, D.; Csucs, G.; Michelle Grandin, H.; Textor, M. Surface engineering approaches to micropattern surfaces for cell-based assays. Biomaterials 2006, 27 (16), 3044-3063.

(26) Costa, P. F. Bone Tissue Engineering Drug Delivery. Curr. Mol. Biol. Reports 2015, 1 (2), 87-93.

(27) Lasseuguette, E.; Roux, D.; Nishiyama, Y. Rheological properties of microfibrillar 
ACS Sustainable Chemistry \& Engineering. Last update: 09.02.2018.

suspension of TEMPO-oxidized pulp. Cellulose 2008, 15 (3), 425-433.

(28) Vallejos, M. E.; Felissia, F. E.; Kruyeniski, J.; Area, M. C. Kinetic study of the extraction of hemicellulosic carbohydrates from sugarcane bagasse by hot water treatment. Ind. Crops Prod. 2015, 67, 1-6.

(29) Ehman, N. V.; Rodriguez Rivero, G.; Area, M. C.; Felissia, F. E. Dissolving pulps by oxidation of the cellulosic fraction of lignocellulosic waste. Cellul. Chem. Technol. 2017, 51 (9-10), 863-870.

(30) Nordli, H. R.; Chinga-Carrasco, G.; Rokstad, A. M.; Pukstad, B. Producing ultrapure wood cellulose nanofibrils and evaluating the cytotoxicity using human skin cells. Carbohydr. Polym. 2016, 150, 65-73.

(31) Chinga-Carrasco, G. Optical methods for the quantification of the fibrillation degree of bleached MFC materials. Micron 2013, 48, 42-48.

(32) Clauser, N. M.; Gutiérrez, S.; Area, M. C.; Felissia, F. E.; Vallejos, M. E. Alternatives of Small-Scale Biorefineries for the Integrated Production of Xylitol from Sugarcane Bagasse. J. Renew. Mater. 2017.

(33) Clauser, N. M.; Gutiérrez, S.; Area, M. C.; Felissia, F. E.; Vallejos, M. E. Small-sized biorefineries as strategy to add value to sugarcane bagasse. Chem. Eng. Res. Des. $2016,107,137-146$.

(34) Lei, Y.; Liu, S.; Li, J.; Sun, R. Effect of hot-water extraction on alkaline pulping of bagasse. Biotechnol. Adv. 2010, 28 (5), 609-612.

(35) Rocha, G. J. M.; Gonçalves, A. R.; Oliveira, B. R.; Olivares, E. G.; Rossell, C. E. V. Steam explosion pretreatment reproduction and alkaline delignification reactions performed on a pilot scale with sugarcane bagasse for bioethanol production. Ind. Crops Prod. 2012, 35 (1), 274-279. 
ACS Sustainable Chemistry \& Engineering. Last update: 09.02.2018.

(36) Djafari Petroudy, S. R.; Syverud, K.; Chinga-Carrasco, G.; Ghasemain, A.; Resalati, H. Effects of bagasse microfibrillated cellulose and cationic polyacrylamide on key properties of bagasse paper. Carbohydr. Polym. 2014, 99, 311-318.

(37) Serra, A.; González, I.; Oliver-Ortega, H.; Tarrès, Q.; Delgado-Aguilar, M.; Mutjé, P. Reducing the Amount of Catalyst in TEMPO-Oxidized Cellulose Nanofibers: Effect on Properties and Cost. Polymers (Basel). 2017, 9 (11), 557.

(38) Pääkkönen, T.; Dimic-Misic, K.; Orelma, H.; Pönni, R.; Vuorinen, T.; Maloney, T. Effect of xylan in hardwood pulp on the reaction rate of TEMPO-mediated oxidation and the rheology of the final nanofibrillated cellulose gel. Cellulose 2016, 23 (1), 277-293.

(39) de Nooy, A. E. J.; Besemer, A. C.; van Bekkum, H. Highly selective nitroxyl radicalmediated oxidation of primary alcohol groups in water-soluble glucans. Carbohydr. Res. 1995, 269 (1), 89-98.

(40) Bowman, M. J.; Dien, B. S.; O’Bryan, P. J.; Sarath, G.; Cotta, M. A. Selective chemical oxidation and depolymerization of switchgrass (Panicum virgatum L.) xylan with oligosaccharide product analysis by mass spectrometry. Rapid Commun. Mass Spectrom. 2011, 25 (7), 941-950.

(41) Gamelas, J. A. F.; Pedrosa, J.; Lourenço, A. F.; Mutjé, P.; González, I.; Chinga-Carrasco, G.; Singh, G.; Ferreira, P. J. T. On the morphology of cellulose nanofibrils obtained by TEMPO-mediated oxidation and mechanical treatment. Micron 2015, 72, 28-33.

(42) Heggset, E. B.; Chinga-Carrasco, G.; Syverud, K. Temperature stability of nanocellulose dispersions. Carbohydr. Polym. 2017, 157, 114-121.

(43) Aksu, P.; Nur, G.; Gülkan, S.; Erciyas, A.; Tayfa, Z.; Allahverdi, T. D.; Allahverdi, E. Genotoxic and cytotoxic effects of formic acid on human lymphocytes in vitro. Turkish Bull. Hyg. Exp. Biol. 2016, 73 (2), 111-120. 
ACS Sustainable Chemistry \& Engineering. Last update: 09.02.2018.

(44) Alexandrescu, L.; Syverud, K.; Gatti, A.; Chinga-Carrasco, G. Cytotoxicity tests of cellulose nanofibril-based structures. Cellulose 2013, 20 (4), 1765-1775.

(45) Bhattacharjee, J. W.; Saxena, R. P.; Zaidi, S. H. Experimental studies on the toxicity of bagasse. Environ. Res. 1980, 23 (1), 68-76.

(46) Jawaid, M.; Mohammad, F. Nanocellulose and Nanohydrogel Matrices; Jawaid, M., Mohammad, F., Eds.; Wiley-VCH Verlag GmbH \& Co. KGaA: Weinheim, Germany, 2017.

(47) Yu, T.; Malugin, A.; Ghandehari, H. Impact of Silica Nanoparticle Design on Cellular Toxicity and Hemolytic Activity. ACS Nano 2011, 5 (7), 5717-5728.

(48) Li, Y.; Sun, L.; Jin, M.; Du, Z.; Liu, X.; Guo, C.; Li, Y.; Huang, P.; Sun, Z. Size-dependent cytotoxicity of amorphous silica nanoparticles in human hepatoma HepG2 cells. Toxicol. Vitr. 2011, 25 (7), 1343-1352.

(49) Sun, L.; Li, Y.; Liu, X.; Jin, M.; Zhang, L.; Du, Z.; Guo, C.; Huang, P.; Sun, Z. Cytotoxicity and mitochondrial damage caused by silica nanoparticles. Toxicol. Vitr. 2011, 25 (8), 1619-1629.

(50) Bhat, S. A.; Singh, J.; Vig, A. P. Genotoxicity reduction in bagasse waste of sugar industry by earthworm technology. Springerplus 2016, 5 (1), 1186.

(51) Rodrigues Filho, G.; Toledo, L. C.; Cerqueira, D. A.; de Assunção, R. M. N.; da Silva Meireles, C.; Otaguro, H.; Rogero, S. O.; Lugão, A. B. Water flux, DSC, and cytotoxicity characterization of membranes of cellulose acetate produced from sugar cane bagasse, using PEG 600. Polym. Bull. 2007, 59 (1), 73-81.

(52) Chia, H. N.; Wu, B. M. Recent advances in 3D printing of biomaterials. J. Biol. Eng. 2015, 9 (1), 4.

(53) Markstedt, K.; Mantas, A.; Tournier, I.; Martínez Ávila, H.; Hägg, D.; Gatenholm, P. 3D 
ACS Sustainable Chemistry \& Engineering. Last update: 09.02.2018.

Bioprinting Human Chondrocytes with Nanocellulose-Alginate Bioink for Cartilage Tissue Engineering Applications. Biomacromolecules 2015, 16 (5), 1489-1496.

(54) Martínez Ávila, H.; Schwarz, S.; Rotter, N.; Gatenholm, P. 3D bioprinting of human chondrocyte-laden nanocellulose hydrogels for patient-specific auricular cartilage regeneration. Bioprinting 2016, 1-2, 22-35.

(55) Siqueira, G.; Kokkinis, D.; Libanori, R.; Hausmann, M. K.; Gladman, A. S.; Neels, A.; Tingaut, P.; Zimmermann, T.; Lewis, J. A.; Studart, A. R. Cellulose Nanocrystal Inks for 3D Printing of Textured Cellular Architectures. Adv. Funct. Mater. 2017, 27 (12), 1604619.

(56) Müller, M.; Öztürk, E.; Arlov, $\varnothing . ;$ Gatenholm, P.; Zenobi-Wong, M. Alginate SulfateNanocellulose Bioinks for Cartilage Bioprinting Applications. Ann. Biomed. Eng. 2017, 45 (1), 210-223.

(57) Leppiniemi, J.; Lahtinen, P.; Paajanen, A.; Mahlberg, R.; Metsä-Kortelainen, S.; Pinomaa, T.; Pajari, H.; Vikholm-Lundin, I.; Pursula, P.; Hytönen, V. P. 3D-Printable Bioactivated Nanocellulose-Alginate Hydrogels. ACS Appl. Mater. Interfaces 2017, 9 (26), 21959-21970.

(58) Rashad, A.; Mustafa, K.; Heggset, E. B.; Syverud, K. Cytocompatibility of Wood-Derived Cellulose Nanofibril Hydrogels with Different Surface Chemistry. Biomacromolecules 2017, $18(4), 1238-1248$.

(59) Liu, J.; Chinga-Carrasco, G.; Cheng, F.; Xu, W.; Willför, S.; Syverud, K.; Xu, C. Hemicellulose-reinforced nanocellulose hydrogels for wound healing application. Cellulose 2016, 23 (5), 3129-3143.

(60) Naderi, A.; Lindström, T.; Sundström, J. Carboxymethylated nanofibrillated cellulose: rheological studies. Cellulose 2014, 21 (3), 1561-1571. 
ACS Sustainable Chemistry \& Engineering. Last update: 09.02.2018.

(61) Moberg, T.; Sahlin, K.; Yao, K.; Geng, S.; Westman, G.; Zhou, Q.; Oksman, K.; Rigdahl, M. Rheological properties of nanocellulose suspensions: effects of fibril/particle dimensions and surface characteristics. Cellulose 2017, 24 (6), 2499-2510.

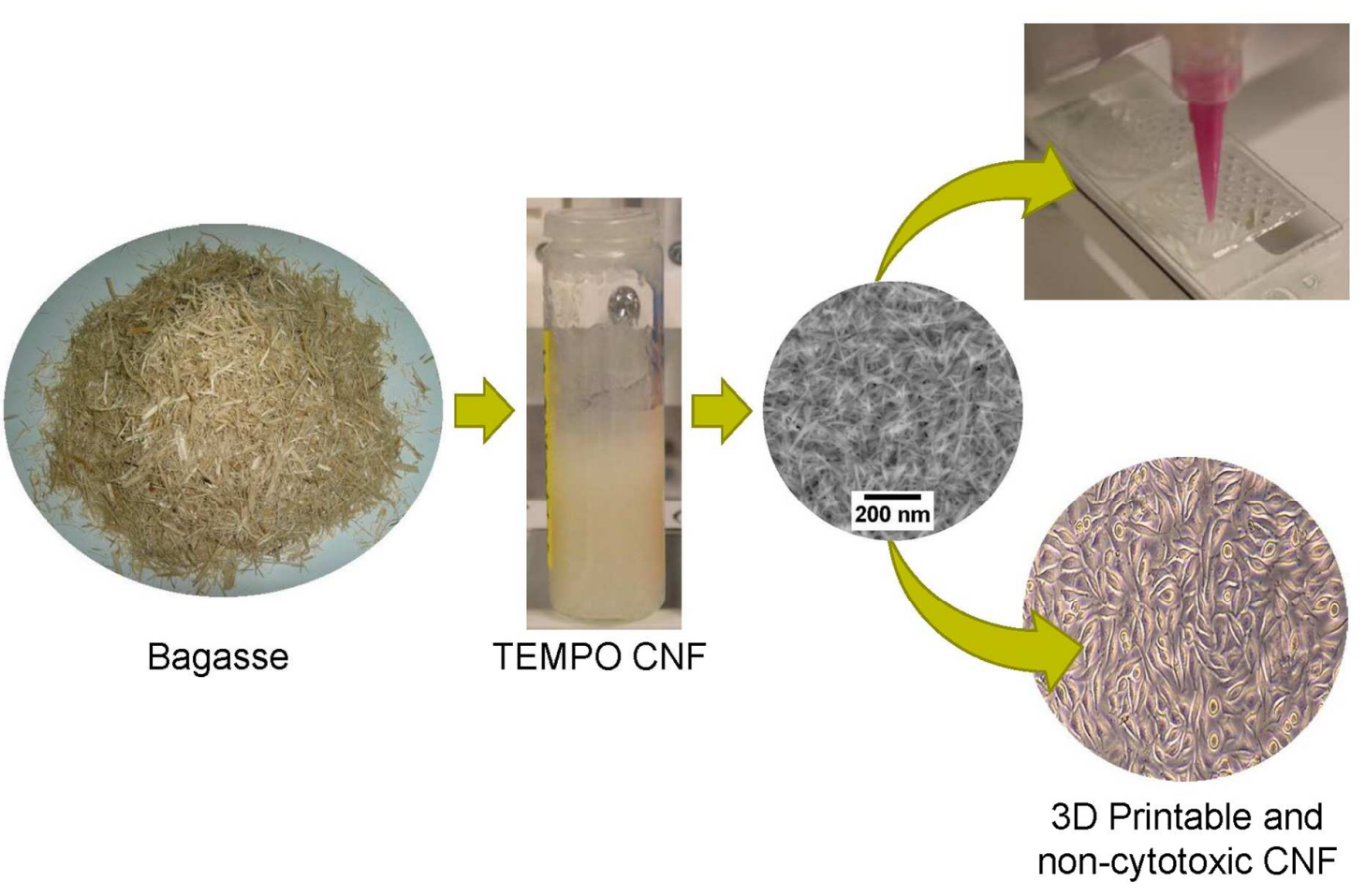

Synopis: Bagasse is an abundant agro-industrial residue that can be used for production of inks for 3D printing of nanocellulose constructs 